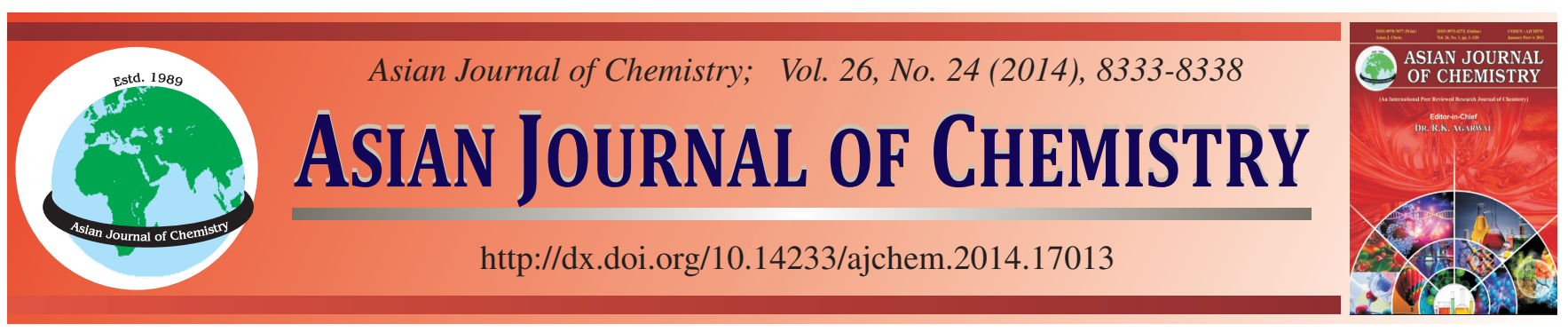

\title{
Comparative Study on Microstructure and Corrosion Resistance of Mg-Al Based Alloy with Mn and Sr Addition
}

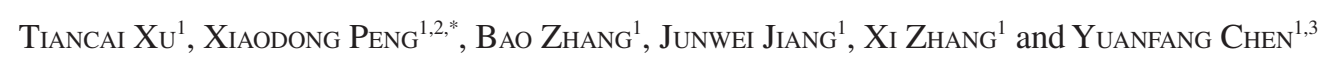

${ }^{1}$ College of Materials Science and Engineering, Chongqing University, Chongqing 400044, P.R. China

${ }^{2}$ Engineering Research Center for Mg Alloys, Chongqing University, Chongqing 400044, P.R. China

${ }^{3}$ College of Materials Science and Engineering, Chongqing University of Technology, Chongqing 400054, P.R. China

*Corresponding author: Tel/Fax: +86 23 65111625, E-mail: 737770318@qq.com

Received: 9 January 2014;

Accepted: 9 April 2014;

Published online: 1 December 2014;

AJC-16355

Magnesium alloys, including Mg-3Al-0.5Mn (AM30), Mg-3Al-0.5Sr (AJ30) and Mg-3Al-0.5Mn-0.5Sr (AMJ300), were designed and prepared in vacuum induction furnace under controlled argon atmosphere. The effects of minor $\mathrm{Sr}$ and $\mathrm{Mn}$ addition on the microstructure and corrosion resistance of the $\mathrm{Mg}-3 \mathrm{Al}$ (wt.\%) alloy were investigated by light and scanning electron microscopy, energy dispersive spectrometry, X-ray diffraction and electrochemical testing. The results indicate that $\mathrm{AM} 30$ alloy is composed of $\alpha-\mathrm{Mg}_{\mathrm{g}} \mathrm{Al}_{11} \mathrm{Mn}_{14}$ phases, whereas the $\mathrm{AJ} 30$ alloy consists of $\alpha-\mathrm{Mg}, \mathrm{Al}_{4} \mathrm{Sr}$ and $\mathrm{Mg}_{17} \mathrm{Sr}_{2}$ phases. Beyond above phases, $\mathrm{AMJ} 300$ alloy is composed of $\mathrm{Mn}$ phase. The $\mathrm{Sr}$ addition refined the as-cast grain structure of $\mathrm{Mg}$-3Al alloy and the grain refining effect of $\mathrm{Sr}$ is more pronounced than $\mathrm{Mn}$ addition at the same level. However, the addition of $\mathrm{Sr}$ is not as effective as the simultaneous addition of $\mathrm{Sr}+\mathrm{Mn}$ for the refinement of grains. Compared to $\mathrm{Sr}, \mathrm{Mn}$ improved the corrosion resistance of binary $\mathrm{Mg}-\mathrm{Al}$. Due to its smallest corrosion current density and corrosion rate, the corrosion resistance of AM30 alloy is proved the best. The highest corrosion rate was observed for AJ30 alloy. The main solid corrosion products were $\mathrm{Mg}(\mathrm{OH})_{2}$.

Keywords: Mg-Al alloys, Mn addition, Sr addition, Grain refinement, Corrosion resistance.

\section{INTRODUCTION}

With energy crisis and attention of environment protection, light-weight and recyclable materials are in great need. As the lightest engineering material among metallic structural materials, magnesium alloy is possessed of several advantages including high thermal conductivity, high specific stiffness, high damping capacity, excellent machinability, good castability and recyclability ${ }^{1-4}$. Therefore, magnesium alloys have a potential for use as a structure and engineering material in many fields such as aerospace, electronic, automobile indus$\operatorname{tries}^{5,6}$. However, the corrosion performance of magnesium alloy is a major obstacle to its wider structural applications ${ }^{7}$.

Strontium and manganese are two important additives used in magnesium alloys. As a representative alkaline-earth element, Sr has also been considered for alloying with $\mathrm{Mg}$ alloys.

The alloying effects of strontium on magnesium alloys, e.g., $\mathrm{Mg}$-Al based alloys, have been found to display superior creep performance and excellent high-temperature properties ${ }^{8}$. Recently, several studies have demonstrated the industrial use of Sr, especially for the modification of Al-Si alloys'. These results suggest the potential use of $\mathrm{Sr}$ as an additive for realizing grain refinement in $\mathrm{Mg}-\mathrm{Al}$ alloy series ${ }^{10}$. Nevertheless, there were few reports about the effects of $\mathrm{Sr}$ on the corrosion resistance of $\mathrm{Mg}-\mathrm{Al}$ alloy. Instead, it has been reported that the addition of $\mathrm{Mn}$ transforms $\mathrm{Fe}$ and certain other impurities in the magnesium alloy to relatively harmless intermetallic compounds. Furthermore, Mn addition contributes to grain refinement and high formability during extrusion ${ }^{11-13}$. Meanwhile, the combinative role of $\mathrm{Sr}$ and $\mathrm{Mn}$ on the microstructure and corrosion resistance of magnesium alloy has not been systematically investigated.

Therefore, the aim of this work was to investigate the effect of $\mathrm{Mg}-\mathrm{Sr}$ and $\mathrm{Mg}-\mathrm{Mn}$ master alloys addition on the microstructure and corrosion resistance of the as-cast $\mathrm{Mg}-3 \mathrm{Al}$ alloy.

\section{EXPERIMENTAL}

The alloy was prepared using $99.9 \%$ pure ingots of $\mathrm{Mg}$ and Al. Master alloys were prepared in the composition of $\mathrm{Mg}-5 \% \mathrm{Mn}$ and $\mathrm{Mg}-5 \% \mathrm{Sr}$ (mass fraction), which contained $\mathrm{Mn}$ and $\mathrm{Sr}$, respectively. The materials were first loaded in a graphite crucible, which was mounted in a vacuum induction furnace. Subsequently, the furnace chamber was evacuated 
and maintained at a pressure of $1 \times 10^{-1} \mathrm{~Pa}$. Prior to melting, Ar gas was introduced into the chamber and maintained at standard atmospheric pressure during melting. The melt was maintained at $720{ }^{\circ} \mathrm{C}$ for $0.5 \mathrm{~h}$, without stirring the mixture. Following that, the melt was cast in a permanent mold of dimension $90 \mathrm{~mm} \times 300 \mathrm{~mm}$, which was preheated to a temperature of $280{ }^{\circ} \mathrm{C}$. The as-cast specimens of $\mathrm{Mg}-3 \mathrm{Al}-0.5 \mathrm{Mn}$, $\mathrm{Mg}-3 \mathrm{Al}-0.5 \mathrm{Sr}$ and $\mathrm{Mg}-3 \mathrm{Al}-0.5 \mathrm{Mn}-0.5 \mathrm{Sr}$ were machined from $\Phi 90$ to $\Phi 80 \mathrm{~mm}$. Following that, the homogenization treatment was conducted in a vacuum furnace at $380{ }^{\circ} \mathrm{C}$ for $12 \mathrm{~h}$. For the homogenization treatment, the furnace chamber was evacuated to $1 \times 10^{-1} \mathrm{~Pa}$, with the supply of Ar at atmospheric pressure during the homogenization. Chemical compositions of the ingots were verified by taking X-ray fluorescence spectrometry at the center of the ingots. The corresponding results are summarized in Table-1.

\begin{tabular}{cccccc}
\multicolumn{5}{c}{ TABLE-1 } \\
\multicolumn{5}{c}{ ACTUAL CHEMICAL COMPOSITIONS } \\
OF THE EXPERIMENTAL ALLOYS, wt \% \\
\hline Alloy & \multirow{2}{*}{ Alloy } & \multicolumn{5}{c}{ Mass fraction (\%) } \\
\cline { 3 - 6 } treatment & & $\mathrm{Al}$ & $\mathrm{Mn}$ & $\mathrm{Sr}$ & $\mathrm{Mg}$ \\
\hline \multirow{3}{*}{ As-cast } & $\mathrm{Mg}-3 \mathrm{Al}-0.5 \mathrm{Mn}$ & 3.12 & 0.51 & - & $\mathrm{Bal}$ \\
& $\mathrm{Mg}-3 \mathrm{Al}-0.5 \mathrm{Sr}$ & 3.09 & - & 0.45 & $\mathrm{Bal}$ \\
& $\mathrm{Mg}-3 \mathrm{Al}-0.5 \mathrm{Mn}-0.5 \mathrm{Sr}$ & 3.31 & 0.49 & 0.51 & Bal. \\
\hline
\end{tabular}

The electrochemical measurements were conducted using CHI660 electrochemical workstation. The corrosive medium was $3.5 \% \mathrm{NaCl}$ solution and the three-electrode system was used with 232 model saturated calomel electrode as reference electrode, the as-cast experimental alloy as working electrode and 213 model Pt electrode as auxiliary electrode. Different alloy specimens of Tafel polarization curve were tested respectively. And the scan range from 0.4 to $2.2 \mathrm{~V}$, the scanning rate was $10 \mathrm{mV} / \mathrm{s}$.

The salt spray test was performed in the FQY025 salt spray cabinet at room temperature for $48 \mathrm{~h}$. The corrosive medium was $3.5 \% \mathrm{NaCl}$ solution and the $\mathrm{pH}$ value was 7.5. The tested specimens were gently washed by water after the test and dipped into the solution of $200 \mathrm{~g} / \mathrm{L} \mathrm{CrO}_{3}$ and $10 \mathrm{~g} / \mathrm{L} \mathrm{AgNO}_{3}$ for $5 \mathrm{~min}$ to remove the salt deposits from the surface, then washed by acetone and distilled water and immediately dried and finally weighed ${ }^{14}$.

The metallographic specimens were cut from the same position after each casting step. The cut specimens were polished and etched in an $8 \%$ nitric acid solution in distilled water and a solution of $1.5 \mathrm{~g}$ picric, $25 \mathrm{~mL}$ ethanol, $5 \mathrm{~mL}$ acetic acid and $10 \mathrm{~mL}$ distilled water. The obtained specimens were analyzed by using optical microscope (olympus) and scanning electron microscope (SEM, JOEL/JSM-6460LV) equipped with an Oxford energy-dispersive X-ray spectroscope (EDS). In addition, the crystalline phase of the specimens was identified by using X-ray diffraction (XRD, D/MAX-A) analysis.

\section{RESULTS AND DISCUSSION}

Microstructure of alloys: Fig. 1 shows the microstructure of the as-cast experimental alloys. It is observed from Fig. 1 that the intermetallic phase is distributed between the dendrites of primary $\alpha-\mathrm{Mg}$ matrix phase. XRD patterns of as-cast AM30, AJ30 and AMJ300 alloys are presented in Fig. 2. The results indicate that $\mathrm{AM} 30$ alloy is composed of $\alpha-\mathrm{Mg}$ and $\mathrm{Al}_{11} \mathrm{Mn}_{14}$ phases, whereas the AJ30 alloy consists of $\alpha-\mathrm{Mg}, \mathrm{Mg}_{17} \mathrm{Sr}_{2}$ and $\mathrm{Al}_{4} \mathrm{Sr}$ phases. Beyond above phases, AMJ300 alloy is composed of Mn phase. Furthermore, we observe that the $\mathrm{Mg}_{17} \mathrm{Sr}_{2}$ peaks increase in AMJ300 alloy. The contrast tomography indicates significant broadening of the weak diffraction patterns of $\mathrm{Mg}_{17} \mathrm{Sr}_{2}$ and $\mathrm{Mn}$ precipitated in the AMJ300 alloy.

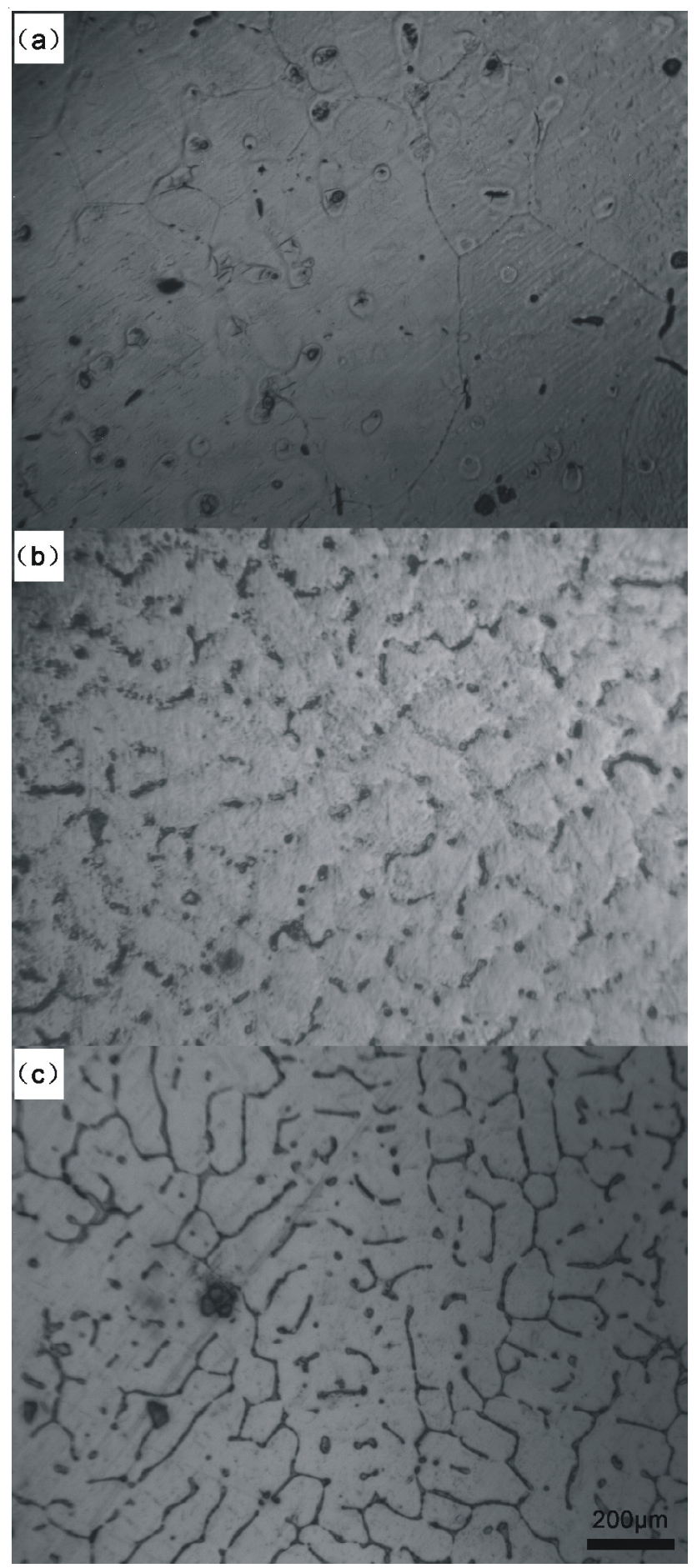

Fig. 1. Optical micrographs showing the microstructure of the investigated alloys in as-casting: (a) Mg-3Al-0.5 Mn; (b) Mg-3Al-0.5Sr; (c) $\mathrm{Mg}-3 \mathrm{Al}-0.5 \mathrm{Mn}-0.5 \mathrm{Sr}$ 


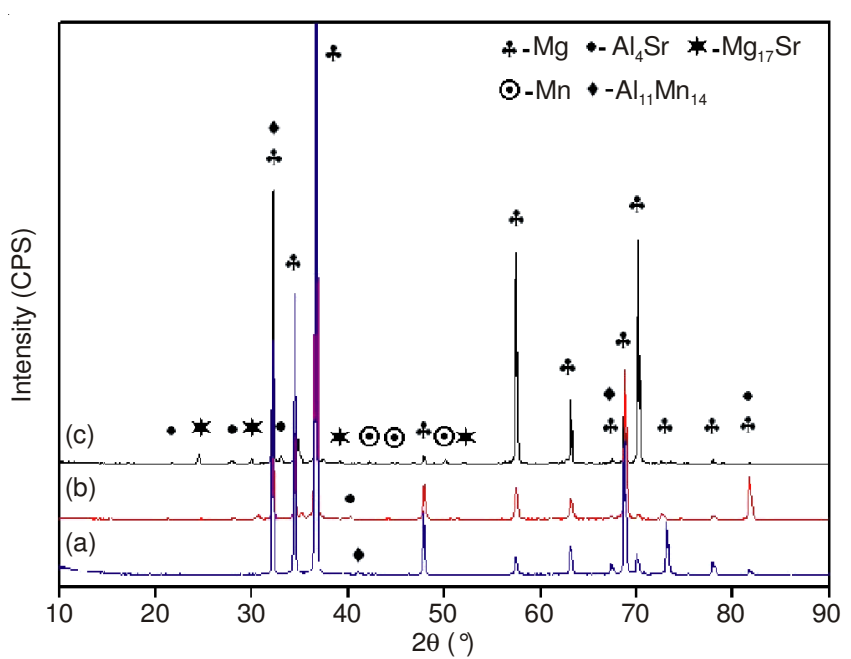

Fig. 2. X-ray diffraction patterns of the investigated alloys in as-casting: (a) $\mathrm{Mg}-3 \mathrm{Al}-0.5 \mathrm{Mn}$; (b) Mg-3Al-0.5Sr; (c) Mg-3Al-0.5Mn-0.5Sr

It is found from Fig. 1 that the secondary dendrite arm spacinging (DAS) of the $\alpha-\mathrm{Mg}$ phases in the Sr-containing alloys, which was measured by the standard linear intercept method, are relatively smaller than $\mathrm{Mg}-3 \mathrm{Al}-0.5 \mathrm{Mn}$ alloy (Table-2) and with increasing $\mathrm{Sr}$, the boundary line of the $\mathrm{Mg}$ phases in the as-cast experimental alloys present more clearly ${ }^{15}$. The above results preliminarily indicate that adding $0.5 \mathrm{wt} \%$ $\mathrm{Sr}$ to the $\mathrm{Mg}-3 \mathrm{Al}$ alloy can refine the grains of the alloy and the refining effect of $\mathrm{Sr}$ is better than $\mathrm{Mn}$ under the same conditions. However, the addition of $\mathrm{Sr}$ is not as effective as the simultaneous addition of $\mathrm{Sr}+\mathrm{Mn}$ for the refinement of grains. The secondary dendrite arm spacing (DAS) of the primary $\alpha-\mathrm{Mg}$ phases in $\mathrm{Mg}-3 \mathrm{Al}-0.5 \mathrm{Mn}-0.5 \mathrm{Sr}$ alloy is the smallest and the boundary line is the most clearly shown in Fig. 1c.

\begin{tabular}{cccc}
\multicolumn{4}{c}{ TABLE-2 } \\
DENDRITE ARM SPACING (DAS) OF THE \\
AS-CAST EXPERIMENTAL ALLOYS \\
\hline $\begin{array}{c}\text { Experimental } \\
\text { alloys }\end{array}$ & $\mathrm{Mg}-3 \mathrm{Al}-0.5 \mathrm{Mn}$ & $\mathrm{Mg}-3 \mathrm{Al}-0.5 \mathrm{Sr}$ & $\mathrm{Mg}-3 \mathrm{Al}-0.5 \mathrm{Mn}-$ \\
\hline DAS $(\mu \mathrm{m})$ & 189.75 & $(\mathrm{AJ} 30)$ & $0.5 \mathrm{Sr}(\mathrm{AMJ} 300)$ \\
\hline
\end{tabular}

The effect of $\mathrm{Sr}$ addition on the grain size of as-cast $\mathrm{Mg}-\mathrm{Al}$ and $\mathrm{Mg}-\mathrm{Al}-\mathrm{Mn}$ alloys can be explained on the basis of growth restriction factor $(\mathrm{GRF})^{16}$.

$$
\mathrm{GRF}=\sum_{\mathrm{i}} \mathrm{m}_{\mathrm{i}} \mathrm{c}_{0, \mathrm{i}}\left(\mathrm{k}_{\mathrm{i}}-1\right)
$$

Here $m_{i}$ is the slope of the liquidus line in the binary phase diagram, $\mathrm{c}_{0, \mathrm{i}}$ is the initial concentration of component $\mathrm{i}$ and $\mathrm{K}_{\mathrm{i}}$ is the equilibrium partition coefficient of component $i$. Lee and others contend that the refinement mechanism of $\mathrm{Sr}$ in $\mathrm{Mg}$ alloys is GRF mechanism. Sr atoms will be enrichment at the forefront of solid-liquid interface during the solidification quickly, because the solubility of $\mathrm{Sr}$ atoms is low in magnesium, thus preventing $\alpha-\mathrm{Mg}$ crystals grains grow. In general, GRF represents the ability to inhibit grain growth. The greater the value of GRF, stronger is its ability to inhibit grain growth. According to the binary phase diagrams of $\mathrm{Mg}-\mathrm{Sr}$ alloy, $\mathrm{m}_{\mathrm{Sr}}=$ $-3.53, \mathrm{k}_{\mathrm{Sr}}=0.006$ and $\mathrm{m}_{\mathrm{Sr}}\left(\mathrm{k}_{\mathrm{Sr}}-1\right)=3.51^{17}$. Substituting these values in eqn. (1), it can be seen that GRF increases with $\mathrm{Sr}$ content. Accordingly, the grain growth is inhibited with increase in Sr content, realizing the goal of grain refinement.

The as-cast experimental alloys are characterized via SEM equipped with an EDS and a computer-controlled imaging system. The SEM images of the as-cast AM30 alloy shown in Fig. 3a,b, the blocky and short rod-like intermetallic compounds are randomly distributed in the $\alpha-\mathrm{Mg}$ matrixes. From Fig. 3b, quantitative EDS analysis indicates that the atomic ratio of $\mathrm{Al}$ to $\mathrm{Mn}$ at location $\mathrm{A}$ is approximately 11:14. Correlating this with the XRD results reported earlier, we conclude that the blocky and short rod-like of intermetallic compounds are $\mathrm{Al}_{11} \mathrm{Mn}_{14}$. Fig. 3c, d show the SEM morphology and EDS point analysis, respectively, of the as-cast AJ30 alloy. SEM image of the alloy indicates the formation of new intermetallic compound with irregular shape, distributed at the interfaces between the dendrite arms of primary $\alpha-\mathrm{Mg}$ phases. EDS point analysis, which was performed at location $\mathrm{B}$, indicates the presence of $\mathrm{Mg}, \mathrm{Al}$ and $\mathrm{Sr}$. The corresponding atomic ratio of Al to $\mathrm{Sr}$ is estimated to be $4: 1$. Correlating with the XRD results, these compounds may comprise $\mathrm{Al}_{4} \mathrm{Sr}$.

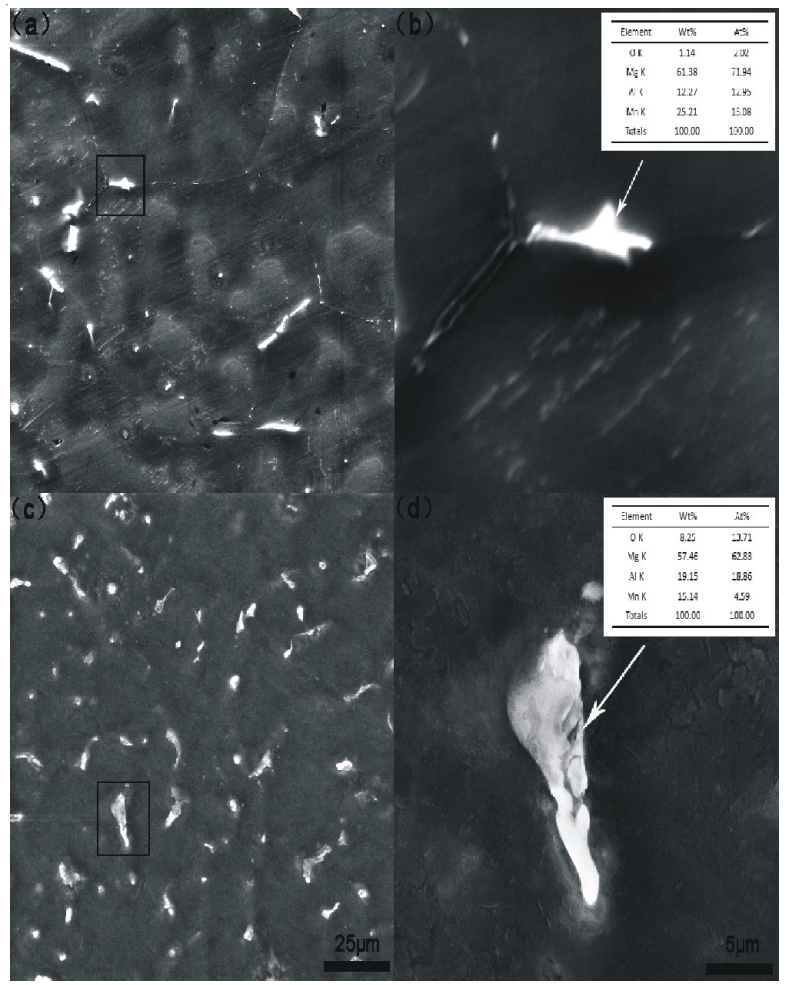

Fig. 3. SEM graph and EDS analysis for the Mg-3Al-0.5Mn alloy (a) (b), Mg-3Al-0.5Sr alloy (c) (d)

SEM images and micro-area chemical composition analysis results of the as-cast AMJ300 alloy are shown in Fig. 4. From the SEM images and the EDS mapping of $\mathrm{Mg}, \mathrm{Al}, \mathrm{Mn}$ and $\mathrm{Sr}$, it can be known that the elements of $\mathrm{Mg}$ are uniformly distributed in the entire alloy matrix, the block compound is a $\mathrm{Mn}$-rich and Al-rich phase and dendrite compound is a Sr-rich and Al-rich phase as given in Fig. 4b-f. Correlating with the $\mathrm{XRD}$ results, these compounds can be related to $\mathrm{Al}_{4} \mathrm{Sr}$ and $\mathrm{Mg}_{17} \mathrm{Sr}_{2}$. 


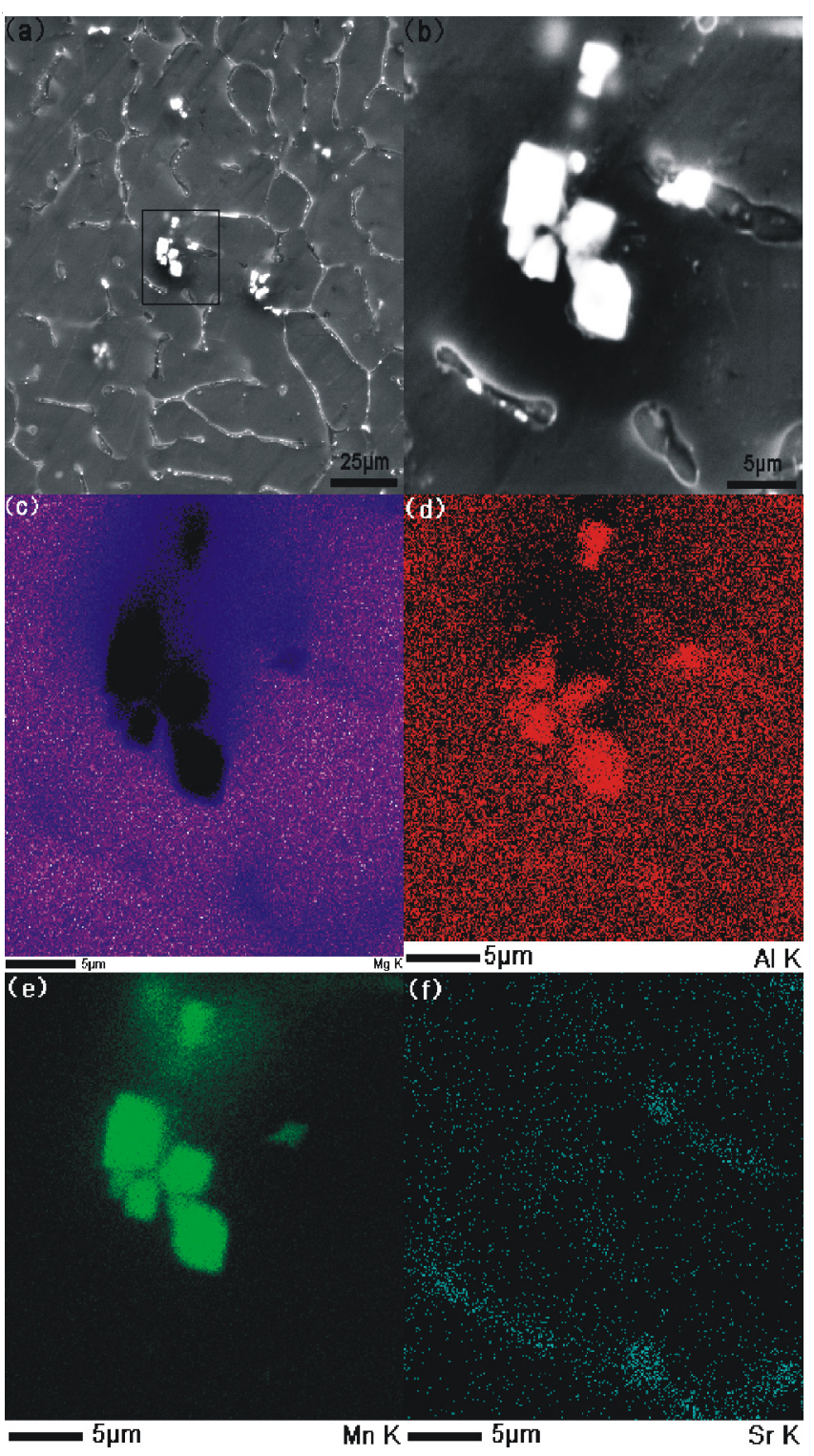

Fig. 4. SEM images and EDS analysis of as-cast Mg-3Al-0.5Mn-0.5 Sr alloy: (a) (b) SEM image, (c) mapping of Mg element, (d) mapping of $\mathrm{Al}$ element, (e) mapping of Mn element, (f) mapping of $\mathrm{Sr}$

Polarization curves: Fig. 5 shows the potentiodynamic Tafel polarization curves of as-cast AM30, AJ30 and AMJ300 alloys in $3.5 \% \mathrm{NaCl}$ solution. It can be concluded that the open circuit voltage, corrosion voltage and corrosion current of experimental alloy solution by the test. The results are listed in Table-2. These data can judge the corrosion-resistance of experiment alloy in the electrolyte solution. Corrosion current density means the pass of electric quantity (the number of coulombs) in unit time and unit area for metallic materials. The corrosion rate of the alloy can be estimated by Faraday's law about the conversion of electrochemical parameters.

$$
\mathrm{V}=\frac{\mathrm{i}_{\text {corr }}}{\mathrm{F}} \times \frac{\mathrm{W}}{\mathrm{n}}=\frac{\mathrm{i}_{\text {corr }}}{\mathrm{F}} \times \mathrm{N}
$$

Here $\mathrm{V}$ is corrosion rate $\left(\mathrm{g} / \mathrm{m}^{2} \mathrm{~h}\right), \mathrm{i}_{\text {corr }}$ is current density $\left(\mathrm{mA} / \mathrm{cm}^{2}\right), \mathrm{N}$ is weight of alloy $(\mathrm{g}), \mathrm{W}$ is atomic weights of metal, $\mathrm{n}$ is the valence number of metallics, $\mathrm{F}$ is Faraday constant $^{18}$. Substituting these values in eqn. (2), it can be seen that $\mathrm{V}$ increases with $\mathrm{i}_{\text {corr }}$. The corrosion rate of alloy can be decided on the base of the Fig. 5 and Table-3. Accordingly, the corrosion rate of AM30 alloy is minimum, the AMJ300 is take second place and the AJ30 alloy is maximum. The corrosion resistance of $\mathrm{Mn}$ is better than $\mathrm{Sr}$ with the same content. The solid solubility of $\mathrm{Mn}$ in $\mathrm{Mg}$ is very low and do not generate intermetallic compounds with $\mathrm{Mg}$. Furthermore, the Mn can generate the high-melting-point intermetallic compounds with $\mathrm{Fe}$ impurity and precipitate out of the $\mathrm{Mg}$ alloy, which seriously damage the $\mathrm{Mg}$ alloy corrosion resistant performance. However, $\mathrm{Sr}$ can react with $\mathrm{Mg}$ and generate the $\mathrm{Mg}_{17} \mathrm{Sr}_{2}$ intermetallic compounds which distributed along the grain boundaries with discontinuous network morphology. This is not good for the corrosion resistance of alloy.

\begin{tabular}{ccccc}
\multicolumn{6}{c}{ TABLE-3 } \\
TAFEL FITTING RESULTS OF POLARIZATION \\
CURVES OF THE AS-CAST EXPERIMENTAL ALLOYS \\
\hline \multirow{2}{*}{ Alloy } & $\begin{array}{c}\text { Time } \\
(\mathrm{min})\end{array}$ & $\begin{array}{c}\text { Open circuit } \\
\text { voltage } \\
(\mathrm{V})\end{array}$ & $\begin{array}{c}\text { Corrosion } \\
\text { voltage } \\
(\mathrm{V})\end{array}$ & $\begin{array}{c}\text { Corrosion } \\
\text { current density } \\
(\mu \mathrm{A} \mathrm{cm})^{-2}\end{array}$ \\
\hline $\mathrm{Mg}-3 \mathrm{Al}-0.5 \mathrm{Mn}$ & 6 & -1.3106 & -1.2218 & 145.31 \\
$\mathrm{Mg}-3 \mathrm{Al}-0.5 \mathrm{Sr}$ & 6 & -1.4115 & -1.3201 & 342.37 \\
$\mathrm{Mg}-3 \mathrm{Al}-0.5 \mathrm{Mn}-0.5 \mathrm{Sr}$ & 6 & -1.5569 & -1.4483 & 152.72 \\
\hline
\end{tabular}

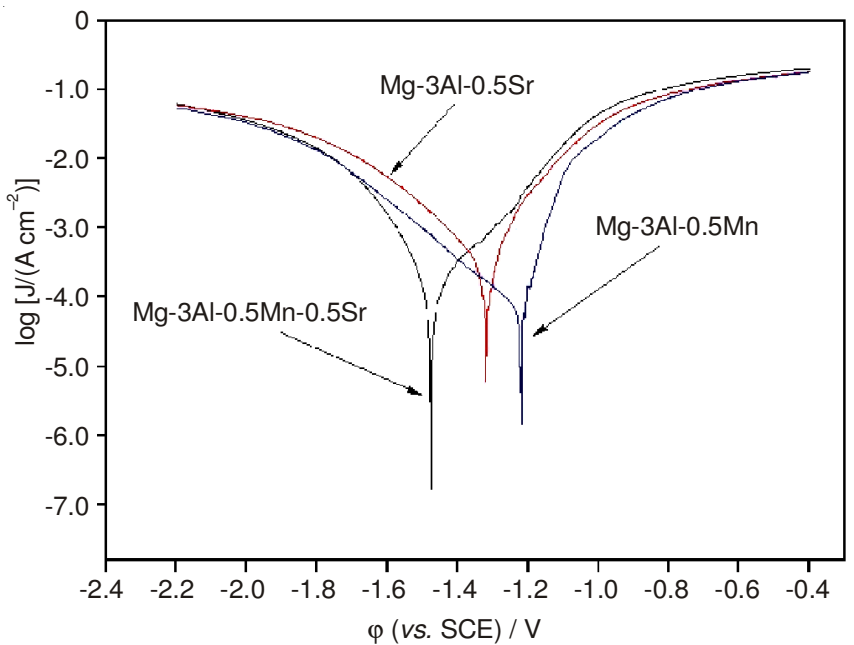

Fig. 5. Tafel polarization curves of the investigated alloys in $3.5 \% \mathrm{NaCl}$ solution

Fig. 6 shows the surfaces of the corroded alloys after electrochemistry corrosion in $3.5 \% \mathrm{NaCl}$ solution. After tests, the surfaces of all the samples are covered by corrosion products, which are composed of globular particles. The corrosion morphology of these three alloys is the typical pitting corrosion. From the Fig. 6a,d,g it can be founded that the amount and area of globular particles on AM30 is minimum, the AMJ300 is takes second place and the AJ30 alloy is maximum, which reflects the corrosion resistance of AM30 is the best while the AJ30 alloy is worst. Most of the corrosion products drop from the surface of AJ30 and AMJ300 alloy specimens. The Al-Sr phases white granule and fibre shapes are covered around chapped corrosion area and there are some Al-Sr phases in the crack of corrosion area (Fig. 6e,f,h,i). Fig. 6 also indicated that the centre of the grain had less pittings than the outside of the grain. Accordingly, $\mathrm{Al}-\mathrm{Sr}$ and $\mathrm{Mg}-\mathrm{Sr}$ intermetallic compounds in the gap of $\alpha-\mathrm{Mg}$ dendritic crystal are the main reason 


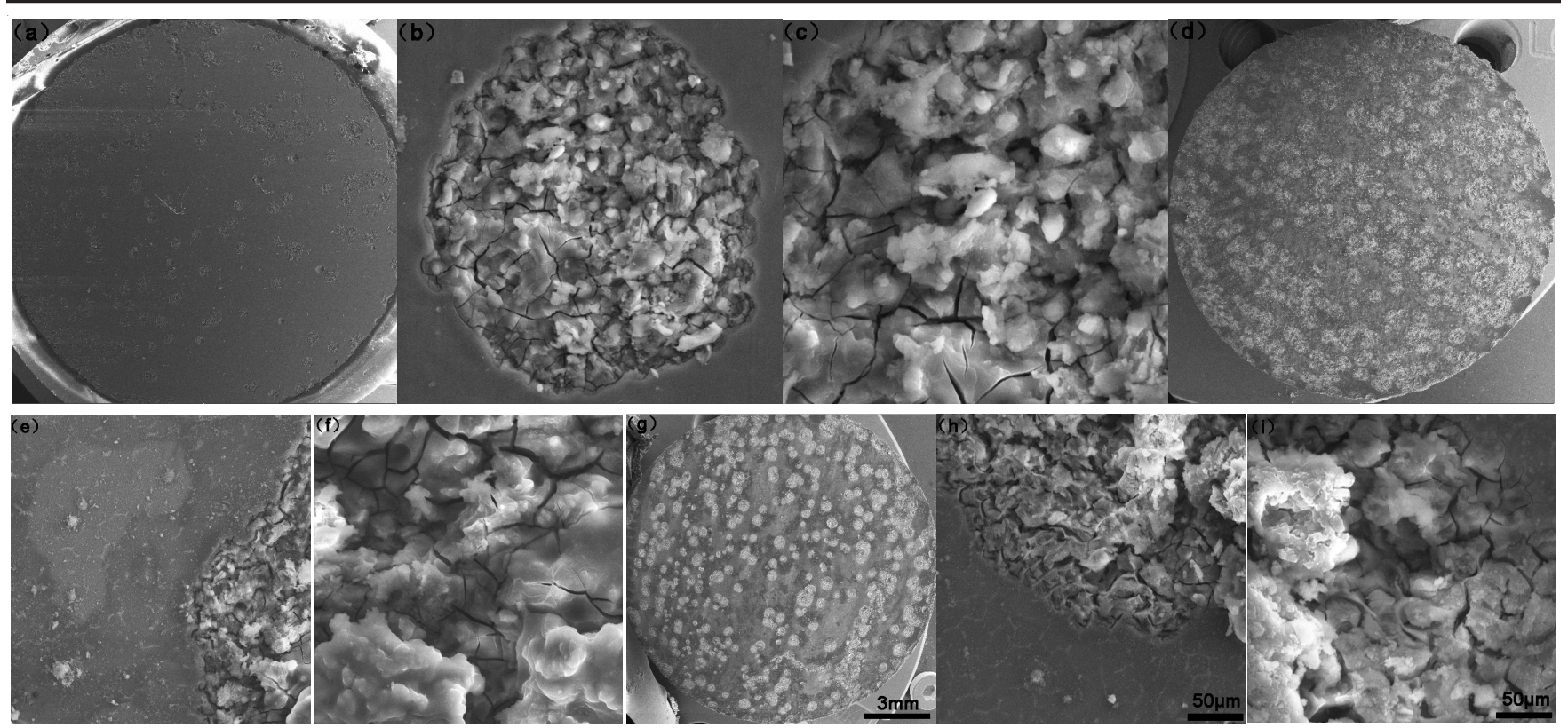

Fig. 6. Micro-corrosion morphology of the investigated alloys: (a) (b) (c) Mg-3Al-0.5Mn; (d) (e) (f) Mg-3Al-0.5Sr; (g) (h) (i) Mg-3Al-0.5Mn-0.5Sr

about anticorrosion ability decline. Consequently, the corrosion mode and corrosion rate were associated with the quantity of $\mathrm{Al}-\mathrm{Sr}$ phases and $\mathrm{Mg}-\mathrm{Sr}$ phases concentration of the $\alpha-\mathrm{Mg}$ phase boundaries. However, the specimen of AM30 alloy is etched, as shown in Fig. 6a, b,c. Therefore, AM30 specimen is corroded slightly and its surface is just of selective corrosion, which is consistent with the corrosion rate of the alloy.

Analysis of salt spray test: The mass loss rate curve of as-cast AM30, AJ30 and AMJ300 alloys immersed in $3.5 \%$ $\mathrm{NaCl}$ solution for $24 \mathrm{~h}$ is shown in Fig. 7. The corrosion products were removed from the specimens every $3 \mathrm{~h}$ for the solution continuously measurement. The corrosion rate of AM30 alloy is the minimum of $0.292 \mathrm{mg} /\left(\mathrm{cm}^{2} \mathrm{~h}\right)$ and the corrosion resistance is the best. It is seen that the corrosion rate decreases after simultaneously adding the $\mathrm{Mn}$ to $\mathrm{Mg}-\mathrm{Al}$ alloy. It is indicated that $\mathrm{Mn}$ can improve the corrosion resistance of $\mathrm{Mg}-\mathrm{Al}$ alloy greatly. However, the corrosion rate of AJ30 and AMJ300 alloy is $0.485 \mathrm{mg} /\left(\mathrm{cm}^{2} \mathrm{~h}\right)$ and 0.376 $\mathrm{mg} /\left(\mathrm{cm}^{2} \mathrm{~h}\right)$, respectively. It suggests that the corrosion of

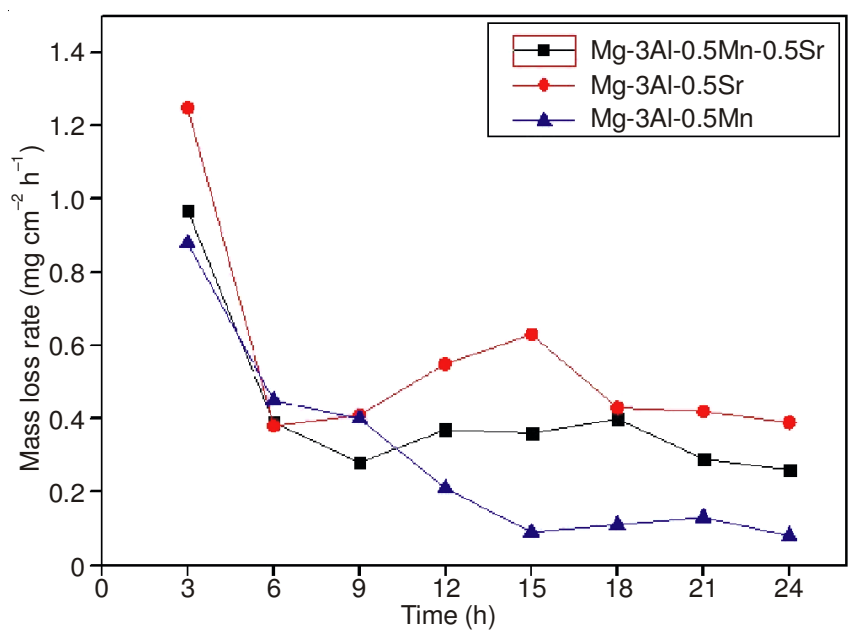

Fig. 7. Mass loss rate curves of the investigated alloys after immersion in $3.5 \% \mathrm{NaCl}$ solution for $24 \mathrm{~h}$
AJ30 and AMJ300 alloys is much worse than that of AM30, which can also reflect that the anti-corrosive function of element $\mathrm{Mn}$ is better than element $\mathrm{Sr}$ in $\mathrm{Mg}-\mathrm{Al}$ alloy.

The XRD patterns of corrosion products on the surface of three samples after immersion are shown in Fig. 8. From Fig. 8, it was found that the corrosion products mainly consisted of $\mathrm{Mg}(\mathrm{OH})_{2}$. The reduction of water and the dissolution of magnesium, respectively is the mainly cathode and anode reaction on the surface of the magnesium alloy in $\mathrm{NaCl}$ solu$\operatorname{tion}^{19,20}$.

$$
\begin{gathered}
2 \mathrm{H}_{2} \mathrm{O}+2 \mathrm{e} \rightarrow \mathrm{H}_{2}+2 \mathrm{OH}^{-} \\
\mathrm{Mg} \rightarrow \mathrm{Mg}^{2+}+2 \mathrm{e}
\end{gathered}
$$

Magnesium ions and hydroxyl ions reaction followed, which will generate soluble or insoluble products depending on the $\mathrm{pH}$ of solution ${ }^{21}$.

$$
\mathrm{Mg}^{2+}+2 \mathrm{OH}^{-} \rightarrow \mathrm{Mg}(\mathrm{OH})_{2}
$$

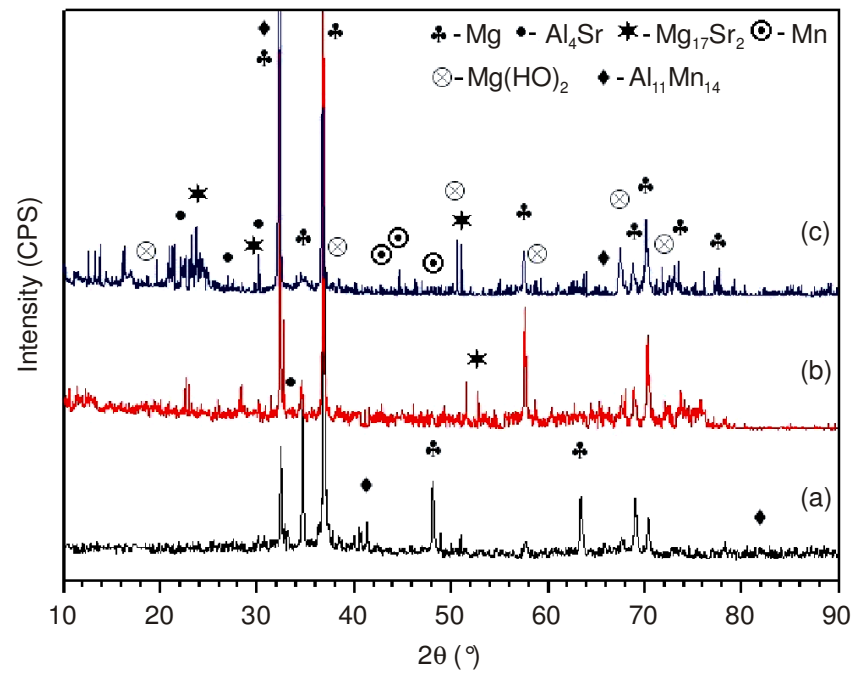

Fig. 8. XRD patterns of the investigated alloys in corroding: (a) Mg-3Al$0.5 \mathrm{Mn}$; (b) Mg-3Al-0.5Sr; (c) Mg-3Al-0.5Mn-0.5Sr 


\section{Conclusion}

With $\mathrm{Sr}$ addition, notable the secondary dendrite arm spacing of the primary $\alpha-\mathrm{Mg}$ phase to be refined and when the $\mathrm{Sr}$ and $\mathrm{Mn}$ were added at same time, the refining effect is the best. The as-cast AM30 alloy comprises $\alpha-M g$ and $\mathrm{Al}_{11} \mathrm{Mn}_{14}$ phases. The addition of $\mathrm{Sr}$ results in the formation of new irregular shaped intermetallic compounds formed and distributed along the dendrite arm of $\alpha-\mathrm{Mg}$ phases with continuous and/or quasi-continuous nets. XRD and EDS analyses show that the precipitated compounds are $\mathrm{Al}_{4} \mathrm{Sr}$ and $\mathrm{Mg}_{17} \mathrm{Sr}_{2}$. Beyond above phases, AMJ300 alloy is composed of Mn phase. According to the corrosion current density and corrosion rate, the corrosion resistance of AJ30 and AMJ300 alloys is much worse than that of AM30, which can also reflect that the anticorrosive function of element $\mathrm{Mn}$ is better than element $\mathrm{Sr}$ in $\mathrm{Mg}-\mathrm{Al}$ alloy.

\section{ACKNOWLEDGEMENTS}

This work was supported by the National Basic Research Program of China (2007CB613702), the Natural Science Foundation of Chongqing Science and Technology Commission, China (2008BB4323), the International Scientific and Technological Cooperation Projects (2010DFR50010).

\section{REFERENCES}

1. A. Atrens, G.-L. Song, F. Cao, Z. Shi and P.K. Bowen, J. Magnesium Alloys, 1, 117 (2013).

2. M. Celikin, A.A. Kaya and M. Pekguleryuz, Mater. Sci. Eng. A, 550, 39 (2012).
3. M. Yang, C. Duan, H. Li, T. Guo and J. Zhang, J. Alloys Comp., 574, 165 (2013)

4. F.Y. Zheng, Y.J. Wu, L.M. Peng, X.W. Li, P.H. Fu and W.J. Ding, J. Magnesium Alloys, 1, 122 (2013).

5. H.-y. Wu, Z.-w. Gao, J.-y. Lin, C.-h. Chiu, J. Alloys Comp., 474, 158 (2009).

6. Q. Yang, T. Zheng, D. Zhang, X. Liu, J. Fan, X. Qiu, X. Niu and J. Meng, J. Alloys Comp., 572, 129 (2013).

7. F.Y. Cao, Z.M. Shi, G.-L. Song, M. Liu, A. Atrens, Corros. Sci., 76, 60 (2013).

8. M. Aljarrah, U. Aghaulor and M. Medraj, Intermetallics, 15, 93 (2007).

9. M. Yang, F. Pan, R. Cheng and A. Tang, J. Mater. Sci., 42, 10074 (2007).

10. X.F. Wan, Y.S. Sun, F. Xue, J. Bai and W.J. Tao, Mater. Sci. Eng. A, 508, 50 (2009).

11. Z.Y. Zhang, L.M. Peng, X.Q. Zeng and W.J. Ding, Transc. Nonferrous Metals Soc. China, 18, s55 (2008).

12. N.D. Nam, M. Mathesh, M. Forsyth and D.S. Jo, J. Alloys Comp., 542, 199 (2012)

13. E. Karaköse and M. Keskin, J. Non-Cryst. Solids, 367, 70 (2013).

14. G. Chen, X.-D. Peng, P.-G. Fan, W.-D. Xie, Q.-Y. Wei, H. Ma, Y. Yang, Trans. Nonferrous Met. Soc. China, 21, 725 (2013).

15. H. Liu, Y. Chen, Y. Tang, S. Wei and G. Niu, J. Alloys Comp., 440, 122 (2007).

16. Y. Tamura, N. Kono, T. Motegi and E. Sato, J. Japan Institute Light Metals, 48, 185 (1998).

17. Y.C. Lee, A.K. Dahle and D.H. St. John, Metallurg. Mater. Trans. A, 31, 2895 (2000).

18. C.Z. Zhang, Metal Corrosion and Protection, Metallurgical Industry Press, Beijing, pp. 89-90 (1985).

19. Y. Song, E.-H. Han, D. Shan, C.D. Yim and B.S. You, Corros. Sci., 65, 322 (2012)

20. X. Zhang, L.I. Yong, J.K. Zhang, C.-S. Wang, H.-W. Li, M.-L. Ma and B.-D. Zhang, Trans. Nonferrous Met. Soc. China, 23, 1226 (2013).

21. W.J. Liu, F.H. Cao, A.N. Chen, L.R. Chang, J.Q. Zhang and C.N. Cao, Corrosion, 68, 045001-1 (2012). 